Dr. Rayner's interest in the mycorrhizal habit, and her scientific collaboration with Prof. W. Neilson Jones, to whom she was married in 1912, both started in 1910 with an inquiry into the ecology of Calluna vulgaris on the Wiltshire and Berkshire Downs. This investigation led a few years later to the publication of a now classical paper for which she was awarded the degree of D.Sc. by the University of London, on "Obligate Symbiosis in Calluna vulgaris". In this paper she established in great detail the nature and extent of the association between $C$. vulgaris and its fungus endophyte, Phoma radicis calluna. Numerous other papers on the endophytic mycorrhiza of heath plants followed, and in 1927 she published her monograph on "Mycorrhiza", as a New Phytologist reprint; more than twenty years later, this monograph is still an invaluable work of reference, as well as a pleasure to read.

As a result of a discussion in Bagley Wood, Oxford, on the occasion of the British Association meeting in 1926 , Dr. Rayner started work on the other large group of mycorrhizal fungi, the ectophyte associates of forest tree roots. This led both to some most interesting fundamental work on the nature of ectophytic mycorrhiza, and to the solution of an important practical problem-the establishment of young conifers on the Wareham Heath area of Dorset, a difficulty that had for some time vexed the Forestry Commission. Later the Commission provided Dr. Rayner with a research nursery and a scientific helper to assist her investigations at Wareham and elsewhere. Dr. Rayner's series of papers on these tree investigations, together with other contributions by herself and Prof. Neilson Jones, were reprinted in 1944 by Messrs. Faber and Faber in a single volume under the title "Problems in Tree Nutrition"-an indication of the wide interest aroused by this work. In recent reports, Dr. Rayner has stressed the importance not only of the compost but also of the system of cultivation used in conjunction with it, for the promotion of maximum fungal activity and for the maintenance of soil fertility in the forest nurseries. Dr. Rayner's precise interpretation of her results on the Wareham Heath plots is still a subject for controversy and further experiment; none would deny, however, that by her striking demonstration of the value of organic composts for the establishment of coniferous seedlings she has been an outstanding benefactor to forestry.

At times, Dr. Rayner was wont to deplore the controversy, not infrequently bitter, that has always ranged around the subject of mycorrhiza, and in which, during her life, she was well to the forefront. Partly as a result of her own work, however, the benefit to the host of the ectophytic mycorrhizal association is now established almost beyond question, even though its mechanism still requires further elucidation. The benefit derived from the endophytic mycorrhizal habit, by heath plants, orchids and others, on which Dr. Rayner insisted so strenuously, has always been harder to prove ; for a long time, the crucial experiment always seemed to be just beyond the grasp of investigators, but recent work suggests that the fungus endophyte may bring about the successful establishment of its seedling host by supplying missing growth factors, as well as by rendering biochemical assistance in other ways, perhaps.

In recent years, Dr. Rayner extended her interests to embrace mycorrhizal associations in a great variety of crops, tropical as well as temperate, and travelled widely in pursuit of her work. To those who knew her well she could be a delightful and stimulating companion, whether in the laboratory or the field, and a visit to her laboratory at Bedford College always gave one plenty to think about. Her long scientific collaboration with her husband, Prof. Neilson Jones, in which temperaments and interests were most happily blended, was a very fruitful one; right up to the last, she had refused to give in to chronic ill. health, and her determination to continue with her work at all costs gained the admiration of all who knew her.

S. D. GarReTT

\section{Mr. G. E. F. Fertel}

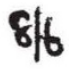

Geoffrey Fertel was born on November 19, 1913, at Bromley, Kent, where his father, who was of Huguenot ancestfy, was well known for his musical ability and Mas enganist at the parish church; his maternal gfold father, Benjamin Harrison, was distiryuiphpy, as an archæologist. While still a small chilf, the showed unusual interest in natural things affijn mechanisms; his love of the countryside was encouraged by his Kentish environment, and at Sevenoaks School he was allowed to spend time on botany instead of games, for which he had no liking. On entering the Imperial College of Science and Technology, London, Fertel decided to study physics, and was soon recognized as a quick and ingenious constructor and experimenter. Though an indefatigable inquisitor of his teachers, Fertbl was never happy until he had 'seen through' a mechanism or a problem in his own way, which usually involved an analogy with some other mechanism or problem, often in another branch of science. $\mathrm{He}$ had little interest in formal science, and less in formal people.

After graduation, he remained at the College as a research student, taking part in developing the new technique of time-of-flight measurements with slow neutrons. He left not long before the outbreak of war to join the physics staff of the University of Bristol ; but there was already no doubt that his great ability to make apparatus work was matched by a power to see clearly the right technical method to apply to any particular scientific problem. At this time, too, his devotion to scientific things began to leave room for personal friendships that grew in number and strength as time went on. He became noted for original demonstration experiments and for technical jokes such as the perfectly constructed lefthanded wood-screw kept in his pocket to hand to a colleague in need, with a right-handed one in the other pocket to be offered as soon as the joke had been enjoyed.

During the War, Fertel worked in the Admiralty Signals Establishment, where his talent for under. standing and making things yielded several devices: of which at least one is still an essential part of Service radar equipment. He was glad to return to university life at Bristol and took part in many activities, not only in the laboratory but also in such pursuits as the exploration of caves, both in England and on the Continent. He left Bristol in 1948 to join in the construction and operation of the large cyclo. tron at the University of Birmingham, and quickly gained the admiration and the affection of his new colleagues. On January 19, 1949, while making adjustments to the cyclotron, he was electrocuted and died instantly.

Fertel left little published work, but will long be remembered as a man of extraordinary energy and skill whose passion was to know and to understand. 